\title{
AN APPLICATION OF LEARNING THEORY TO THE SECONDARY ASPECTS OF STUTTERING
}

\author{
MARGARET MARKS, B.A. (LOG), M.A. (WITWATERSRAND) \\ Senior Lecturer, Department of Speech Pathology \& Audiology, \\ University of the Witwatersrand, Johannesburg
}

\section{SUMMARY}

The concepts of primary and secondary stuttering are re-evoked to provide a framework for a discussion of the theoretical division of stuttering into a series of responses. The stuttering behaviours of an advanced stutterer are divided into those of awareness, avoidance, the 'moment of stuttering', a release response and the utterance of the word. One set of responses, those of avoidance, are treated within various learning theory paradigms, namely, the Mowrer-Ullman hypothesis, chaining, superstition, and an avoidance-escape dichotomy. Although no direct therapeutic implications are deduced from these analogies, the value for the speech pathologist of a knowledge of the principles and techniques of learning theory, is stressed.

\section{OPSOMMING}

Die konsepte van primêre en sekondêre hakkel word weer eens bygebring om 'n raamw erk te verskaf vir ' $n$ bespreking van die teoretiese verdeling van hakkel in 'n reeks response. Die hakkelgedrag van 'n gevorderde hakkelaar word ingedeel in bewustheid, vermyding, die ,oomblik van hakkel", 'n vrylatingsrespons en die uiting van die woord. Een stel response, vermyding, word beskou uit verskillende leerteoretiese paradigmas, naamlik die Mowrer-Ullman hipotese, aaneenskakeling, bygeloof en 'n vermydings-ontvlugtingsdigotomie. Alhoewel geen direkte terapeutiese implikasies afgelei word van hierdie analogieë nie, word die waarde van bekendheid met hierdie beginsels en tegnieke van die leerteorie vir die spraakheelkundige beklemtoon.

Although the terms primary and secondary stuttering have fallen into disrepute, and for good semantic reasons, it seems that a case could be made to conjure them up again, to differentiate between the 'actual' stutter (block, dysfluency, classically conditioned response); and those behaviours which the individual uses in an attempt to cope with this undesirable stutter. While the writer is cognizant of the fact that these two aspects of the stutter are not necessarily mutually exclusive, and that the behaviours described as primary and secondary can co-exist and be displayed by the same stutterer at different times and indeed even in the same stuttering incident, it is the aim of this article to focus on the secondary aspects of the responses which constitute the efforts of the more advanced stutterer to deal with his dysfluency. 
There are many theories which attempt to explain the original, or primary speech breakdown, but there is little serious opposition to the theory which best explains the acquisition of secondary responses, namely, that theory derived from the laws of learning. Van Riper ${ }^{11}$ does not feel that the onset of stuttering can be explained only by learning, but he states that '. . we are convinced that much of the behavior which goes under the name of stuttering is learned behavior. We can account for its variability of symptoms and its consistency of pattern in no other way. We have watched it being learned.' The only other theoreticians who attempt to explain the secondary responses are those who are psychodynamically oriented and, although many speech pathologists would reject such descriptions of secondary symptoms as being revealing of 'motor patterns of nursing .... . cannibalistic muscle patterns, analretentive and anal-expulsive' (Coriat, as quoted by Glauber ${ }^{3}$ ), more acceptance is shown of the principles behind such phrases as 'aggressive symptoms' and 'secondary gains', and some of the intractability of severe stuttering is often ascribed to the stutterer's 'need' to retain his stutter, rather than to the therapist's need to know more about the alleviation of his patient's abnormal speech behaviour.

Neurophysiology is a field which could provide a rationale for some of the bizarre responses which comprise advanced stuttering; within this framework we could possibly seek an explanation for the distractive devices which remain, like albatrosses round the stutterer's neck, in the form of secondary behaviours. These, and other phenomena noted in stuttering, may become logical when considered in neurophysiological terms.

Generally, however, as it has come to be accepted that most, if not all, the secondary responses are learned, the understanding of their acquisition has subsumed a knowledge of the laws of learning, while the therapeutic implications have been based on the principles of behaviour modification. Once the worker is committed to this theoretical viewpoint, he stands to benefit from the findings and knowledge of an extensive literature; he is also faced with the responsibilities which such a commitment, and such a literature, imply. The writer has, in an earlier issue of this Journal ${ }^{6}$, discussed these responsibilities, and considered the difficulties which can arise from a limited understanding, and consequent application, of learning theory as it pertains to stuttering.

For many speech pathologists not formally trained in learning theory, it seems a far cry from the puzzled rat that does not know which way to turn, and from the eccentricities of pigeons' pecking (and of the people who pick out what pigeons should peck at), to the human creature struggling to talk. However, we must realise that a simplistic view of the relationship between animal and human behaviour no longer exists. Most contemporary learning theorists have accepted the complexity of animal behaviour, and are even more aware of the almost unchartable vastness of complicated human behaviour. They are aware, for example, that cognition and language must be considered when accounting for many aspects of human functioning. Terrace, ${ }^{9}$ when defining a particular operation of the learning process (stimulus control) states that 'many topics such as perception, psychophysics, thinking and psycholinguistics ... . are directly suggested by this definition, and (there are) numerous other topics that are not so directly relevant.' 
As previously stated, it is probably in a description of the secondary, acquired behaviours, the speaker's attempts to do something about the feared word or situation, that concepts culled from learning theory are most directly applicable. Some speech pathologists have attempted to use procedures, notably those of reinforcement, to demonstrate control of stuttering. The disparity of results, particularly those of experimenters using punishment, lead Brutten and Shoemaker ${ }^{1}$ to their two-factor theory, a concept which supports the present writer's view, stated in $1966^{5}$, that previous workers had thought of 'the stutter' in too molar, and not molecular enough, a manner and that, in most stuttering incidents shown by an advanced stutterer, there is a sequence of responses which comprise the motor act of stuttering.

In this paper, an attempt is made to represent, diagrammatically, this series of responses and to discuss how learning theory can be used to explain one set of these responses, i.e. the avoidance responses.

The following responses are suggested as being relatively typical of an incident of stuttering; although not all the behaviours occur each time the person stutters, they appear with enough frequency to warrant inclusion:

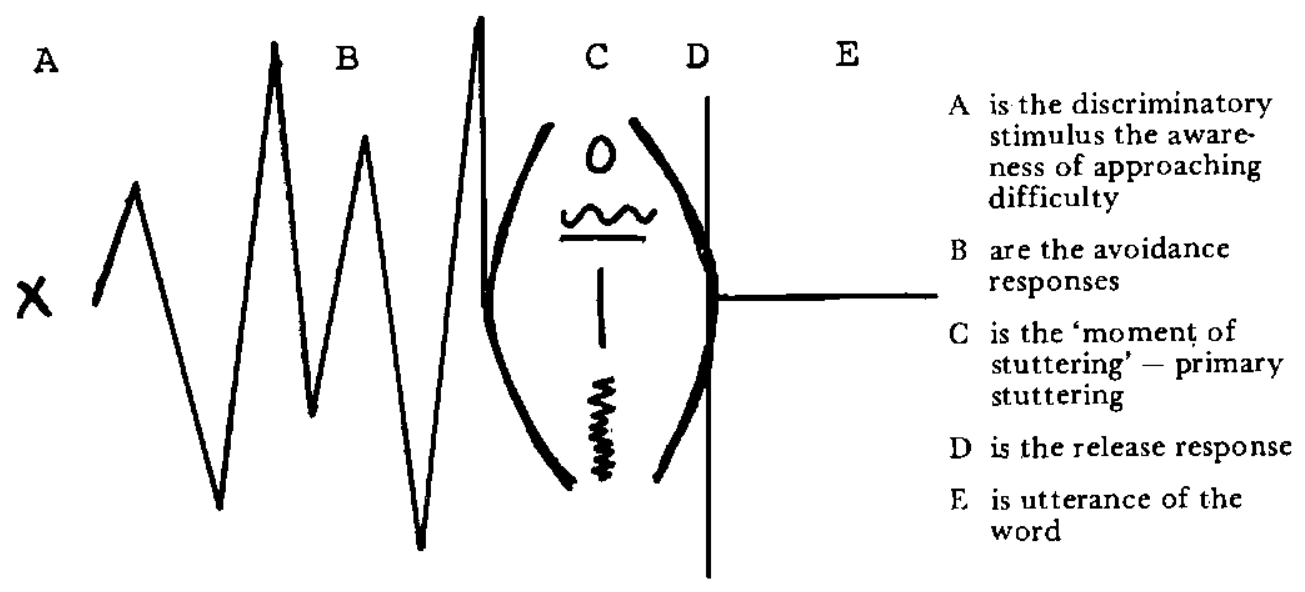

Figure 1: A stuttering incident comprising a series of responses.

A brief description of each of these sets of responses is given.

A-awareness. Something in the stimulus configuration of the speaker's environment acts as a discriminatory stimulus, which initiates the series of responses.

$\mathrm{B}$ - avoidances. These are the responses which have been called by therapists, starters, postponements, interjections, etc. For this paper they will be described only as avoidances. They will be discussed in more depth later, but a graphic representation here indicates their nature.

If 'town' is the feared word in the sentence 'I'm going to town', the following diagrams represent two types of avoidance responses: 


\section{(i) I'm going to.. going to.. t-t-town}

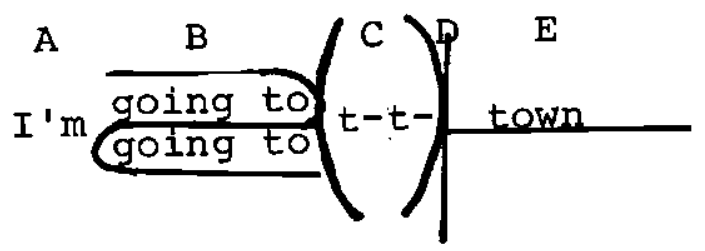

\section{(ii) I'm going to the city}

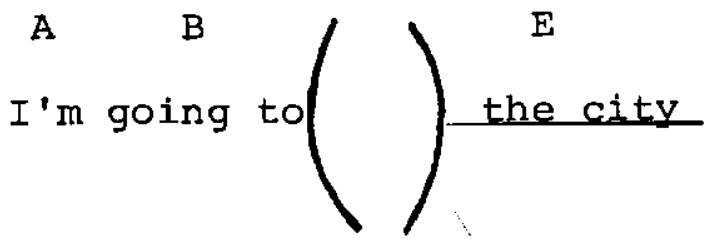

Figure 2: Representations of avoidances.

In (i), the avoidances were not effective as, in addition to using them, the person experienced the stutter $\mathrm{C}$, before uttering the word and so achieving his goal, that of communication.

In (ii), the avoidance, this time one of circumlocution, was successful, and he did not experience $C$, the moment of stuttering, and its consequent $D$, the release response. Although the desired word was not said, the goal of communication was reached.

$\mathrm{C}$ - the moment of stuttering, is represented by various behaviours; the order in which they are listed below indicates increasing amounts of tension.

o - it is possible that there is, in some incidents of stuttering, no 'moment of stuttering', i.e. the stutterer may experience awareness and may utilise responses described under B but, even if he had not done so, would have experienced none of the behaviours described immediately below.

$\sim$ - repetition, either easy or tense, but not as tense or rapid as the behaviours described as tremors. This stage could, depending on the phoneme stuttered on, be represented thus _ longation. Neither of these (repetition and prolongation) is actually a dysfluency, in that they do not interfere with the rhythm of speech, or cause a break in the flow of continued speech.

- block, the actual cessation of ongoing speech movement; it seems as if this occurs mainly, if not only, on stops and vowels.

- tremor, 'fast little vibrations. . . produced by highly tensing the muscles that form a fixed posture'. (Van Riper ${ }^{10}$ ) 
Clinical evidence has lead to the impression that it is the attempt, on the part of the speaker to do something about this moment of stuttering, which gives rise to so much aberrant behaviour. Exactly what aspect of this response is so fearful, is a matter of conjecture; it may be, as Van Riper ${ }^{10}$ implies, the feeling of impotence when the stutterer gets thrown into a tremor; it is also possible the present writer believes, that it is the sound of repetitive speech, be. haviour which was considered as 'stuttering' in childhood, and therefore taboo. Parents often bring their children back to a therapist, saying, in effect: 'we're so pleased; he's stopped stuttering. Of course, he does stop and take a deep breath, but he's not stuttering.' Advanced stutterers, with visually bizarre responses, would rather use these, if they bring with them a reduction in the sound of 'stuttered' speech - they do not see what they look like, but can hear that the feared stutter is not vocalised. 'You'll never get me to spea- speaspeak like that; it sounds ridiculous' is the gist of statements of many stutterers with severe blocks, often accompanied by very visible struggle responses. It may be that the feared aspect of the stuttering moment is not the same for each stutterer, or, indeed, may vary from one stuttering incident to the next, in the same speaker.

D - a release response, which terminates the moment of stuttering. An effortful release is usually more necessary when the moment of stuttering has comprised a block or tremor, than when the speaker is repeating or prolonging, as, in the latter two cases there is little or nothing to be released from. This is seen as a release, rather than an avoidance response, thus supporting Van Riper's ${ }^{11}$ contention that 'it is both psychologically and semantically unwise to stretch the term avoidance to include these escape reactions'.

$\mathrm{E}-$ utterance of the word. This continuation of communication is the reinforcement of all that has gone before.

Once a framework such as the one above is tentatively established as a theoretical point of view, certain questions can be asked, and certain paradigms from learning theory evoked as possible explanations, or as areas deserving further study. Each of the five aspects described could be rephrased in terms of some aspect of learning theory, but only avoidance behaviours and some of their learning theory correlates will be dealt with in this paper.

When the patient comes to therapy, he has his set of premiums: negative for the moment of stuttering, positive for avoidance behaviours. Many therapies are based on the principle of trying to get him to change these premiums, i.e. to want to get to the moment of stuttering; and to want to stop the avoidance behaviour. However, it has been the experience of many therapists that, even though the stutterer tries to stop avoiding, the 'habit' dies hard. Learning theory offers various explanations for behaviours which are deleterious to the well-being of the individual and which are, nevertheless, maintained, behaviours described by Wolpe ${ }^{12}$ as neurotic: 'any persistent habit of unadaptive behaviour acquired by learning in a physiologically normal organism'. Theories based on the principle of learning must account for their persistence in the face of their lack of efficacy in coping in the best possible way with the noxious situation. 
Brutten and Shoemaker ${ }^{1}$ state that both Wischner and Sheehan use the Mowrer-Ullman hypothesis to explain this persistence: 'According to Mowrer and Ullman, if all things are equal, a response will be reinforced or extinguished depending on whether the rewarding or punishing consequences, respectively, follow the cessation of behaviour more closely in time.' Thus the concept of time is considered a crucial factor in the acquisition and retention of aberrant responses.

Another concept which bears scrutiny is that of chaining, first described by Skinner in $1938,{ }^{8}$ and later defined by Ferster and Perrot ${ }^{2}$ as the phenomenon which takes place when a stimulus maintains the preceding performance and also makes possible the next performance in the chain. If, for example, within the behaviours described as $B$ above, there is a sequence of $B^{(1)}$ leading to $B^{(2)}$ leading to $B^{(3)}$ which eventually leads, albeit painfully, to reinforcement $\mathbf{E}$, utterance of the word, each response in the chain is necessary, as it makes $E$ possible. An early work of Luper's ${ }^{4}$ although not explicitly using the term 'chaining' seems to imply the concept, as does a recent experiment reported by Prins and $\mathrm{Lohr}^{7}$. Data from experiments on chaining must lead us to speculate on certain topics, e.g. how certain elements of the chain are learned - i.e. is it possible that they are differentially learned, and will need, therefore, different types of extinguishing procedures? Why are some elements in the chain (which could be called the 'core' of stuttering) present in all incidents of stuttering, while others occur infrequently? Why are some 'distractions' maintained as part of the chain, while others are extinguished? How can information about extinguishing chain behaviour aid in stuttering therapy?

Superstitious behaviour is another description which aids in the understanding of seemingly irrational behaviour. This describes elements in the response not directly instrumental in gaining reinforcement, but which, through association with the operant behaviour, become part of the response gestalt. The classic examples are those of Skinner's pigeons who emit certain responses immediately before the ones which are effective in gaining the desired goal (e.g. turning around before pecking the switch which releases the food, where turning around becomes a superstitious response). Although they were coincidental to the desired behaviour, the responses become part of the total response pattern. It does not seem to be stretching analogies too far if we describe at least some of the stutterer's avoidance responses as superstitious, or ritualistic behaviour. When he considers the intransigence of some of these avoidance behaviours, the clinician will recoginise their similarity to superstitious responses, traditionally difficult to eliminate. As with chaining, we must attempt to utilise knowledge gained by the learning psychologist, in an attempt to break this superstitious behaviour.

Animal experimentation has shown that there is a difference between the learning processes involved in avoidance and escape. Avoidance behaviour is learned by the rat who is faced with an electric grid between it and its desired goal; acquisition of this type of behaviour is different to the learning of behaviours which a second rat must acquire when it is already on the grid and has to discover how to get off - escape behaviour. It seems important to differentiate between these two sets of responses in the stutterer (behaviours $B$ and $D$ ), as it is probable that they are learned differently, require different 
methods of extinction, and that one set may be more difficult to extinguish than the other.

No direct therapeutic implications have been drawn from the analogous nature of stuttering behaviour and that observed by experimental psychologists in their work with controlled units of behaviour, but it seems that a consideration of the relationship between certain aspects of learning and of stuttering could be of benefit to those who seek to help stutterers. There is a rich field of knowledge gained from experiments based on learning theory, and it seems desirable that speech pathologists and therapists adopt and adapt principles and techniques derived from this valuable source of data.

\section{REFERENCES}

1. Brutten, E.J. and Shoemaker, D.J. (1967): The Modification of Stuttering. Prentice-Hall Inc., New Jersey.

2. Ferster, C.B. and Perrott, M.C. (1968): Behavior Principles. AppletonCentury-Crofts, New York.

3. Glauber, I.P. (1968): The Psychoanalysis of Stuttering. In Eisenson, J. (Ed.), Stuttering: A Symposium. Harper and Bros, New York.

4. Luper, H.L. (1956): Consistency of Stuttering in Relation to the Goal Gradient Hypothesis. J. of Speech and Hearing Dis., 21, 336-342.

5. Marks, M. (1966): Stuttering Viewed as a Sequence of Responses. Paper presented to International Seminar in Stuttering and Behavior Therapy. Published in Gray, B.B. and England, G. (1969) Stuttering and the Conditioning Therapies. Monterey Institute for Speech and Hearing, California.

6. Marks, M. (1968): Are we Good Behaviourists? J. of the South African Logopedic Society, 15, 19-25.

7. Prins, D. and Lohr, F. (1972): Behavioral Dimensions of Stuttered Speech. J. of Speech and Hearing Res. 15, 61-71.

8. Skinner, B.F. (1938): The Behavior of Organisms. Appleton-CenturyCrofts, New York.

9. Terrace, H.S. (1966): Stimulus Control. In Honig, W.K. (Ed.) Operant Behavior: Areas of Research and Application. Appleton-Century-Crofts, New York.

10. Van Riper, C. (1963): Speech Correction, Principles and Methods. (4th Edition) Prentice Hall Inc., New Jersey.

11. Van Riper, C. (1971): The Nature of Stuttering. Prentice-Hall Inc,; New Jersey.

12. Wolpe, J. (1958): Psychotherapy by Reciprocal Inhibition Stanford University Press, Stanford and Witwatersrand University Press, Johannesburg. 


\section{Philips Hearing Aid Services}

A Division of S.A. Philips (Pty) Ltd.

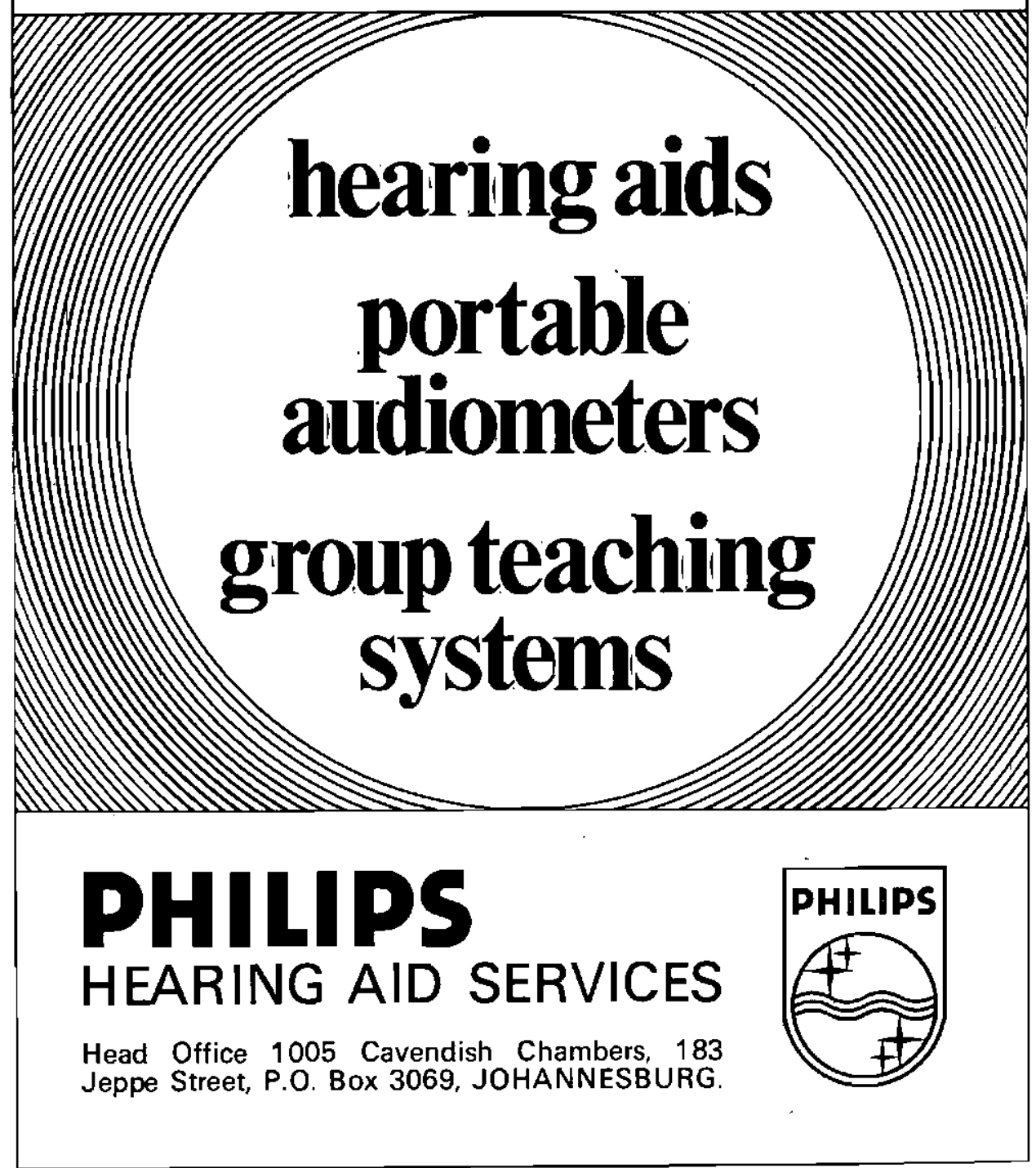

(W01) 44923 